\title{
Discordance of Intraoperative Frozen Section Analysis with Definitive Histology of Sentinel Lymph Nodes in Breast Cancer Surgery: Complementary Axillary Lymph Node Dissection is Irrelevant for Subsequent Systemic Therapy
}

\author{
D. Geertsema, MD ${ }^{1}$, P. D. Gobardhan, $\mathrm{MD}^{1}$, E. V. E. Madsen, $\mathrm{MD}^{1}$, M. Albregts, $\mathrm{MD}^{2}$, J. van Gorp, MD, $\mathrm{PhD}^{3}$, \\ P. de Hooge, $\mathrm{MD}, \mathrm{PhD}^{4}$, and Th. van Dalen, $\mathrm{MD}, \mathrm{PhD}^{1}$ \\ ${ }^{1}$ Division of Surgery, Diakonessen Hospital, Utrecht, The Netherlands; ${ }^{2}$ Department of Radiotherapy, University Medical \\ Centre, Utrecht, The Netherlands; ${ }^{3}$ Division of Pathology, Diakonessen Hospital, Utrecht, The Netherlands; ${ }^{4}$ Division of \\ Nuclear Medicine, Diakonessen Hospital, Utrecht, The Netherlands
}

\begin{abstract}
Background. In breast cancer surgery, intraoperative frozen section (FS) analysis of sentinel lymph nodes (SLNs) enables axillary lymph node dissection (ALND) during the same operative procedure. In case of discordance between a "negative" FS analysis and definitive histology, an ALND as a second operation is advocated since additional lymph node metastases may be present. The clinical implications of the subsequent ALND in these patients were evaluated.

Materials and Methods. Between November 2000 and May 2008, 879 consecutive breast cancer patients underwent surgery including sentinel lymph node biopsy (SLNB) with intraoperative FS analysis of 2 central cuts from axillary SLNs. Following fixation and serial sectioning, SLNs were further examined postoperatively with hematoxylin and eosin (H\&E) and immunohistochemical techniques. For patients with a discordant FS examination, the effect of the pathology findings of the subsequent ALND specimen on subsequent nonsurgical therapy were evaluated.

Results. FS analysis detected axillary metastases in the SLN(s) in 200 patients (23\%), while the definitive pathology examination detected metastases in SLNs in another 151 patients $(17 \%)$. A complementary ALND was
\end{abstract}

(C) The Author(s) 2010. This article is published with open access at Springerlink.com

First Received: 9 November 2009;

Published Online: 27 April 2010

Th. van Dalen, MD, PhD

e-mail: tvdalen@diakhuis.nl performed in 108 of the 151 patients with discordant FS. Additional tumor positive axillary lymph nodes were found in 17 patients (16\%), leading to "upstaging" in $7(6 \%)$. Subsequent nonsurgical treatment was adjusted in 4 patients (4\%): all 4 had more extensive locoregional radiotherapy; no patient received additional hormonal and/ or chemotherapy.

Conclusion. Discordance between intraoperative FS analysis and definitive histology of SLNs is common. In this selection of patients, a substantial proportion had additional lymph node metastases, but postsurgical treatment was rarely adjusted based on the findings of the complementary ALND.

Sentinel lymph node biopsy (SLNB) has replaced axillary lymph node dissection (ALND) for assessing axillary lymph node status in breast cancer patients. ${ }^{1,2}$ Subsequent ALND is done only when the SLN contains metastases because of the risk of additional lymph node metastases in the non-SLNs in the axilla. ${ }^{3,4}$

Intraoperative frozen section (FS) analysis of axillary SLNs enables prompt detection of lymph node metastases. As a result, ALND can be done during the same operative procedure. Despite a "negative" FS result, definitive pathology examination of the SLN will reveal metastases in a number of patients, inherent to the more extensive workup of lymph nodes by serial sectioning and immunohistochemical techniques. In these patients, because of the risk of additional metastases in non-SLNs, an ALND as a second operative procedure is considered necessary for 2 reasons: locoregional control of the axilla and the 
possibility that additional metastatic lymph nodes may influence subsequent nonsurgical therapy.

In a prospective cohort of breast cancer patients staged by SLNB and with the routine use of intraoperative FS analysis we assessed the proportion of patients in whom intraoperative FS analysis revealed no metastases while the definitive pathology examination did detect metastases. In these patients, the clinical implications of a "postponed" ALND were evaluated.

\section{PATIENTS AND METHODS}

Between November 2000 and May 2008, data were collected prospectively regarding 1004 consecutive patients who underwent surgical treatment using SLNB as a staging procedure for clinically staged $\mathrm{T} 1-2 \mathrm{~N} 0$ breast cancer. For the present study, patients were selected who underwent FS analysis of axillary SLNs.

The study group consisted of 879 patients since 125 patients did not undergo FS analysis and were therefore excluded from further analysis. Reasons for not performing FS analysis of SLNs were: small size of the SLNs, that is, when the pathologists deemed the SLNs to small or to fatty for reliable FS analysis $(n=64)$, the introduction of this new staging technique when SLNB was followed by ALND on a routine basis $(n=30)$, clinical trial participation obviating ALND (assignment to the radiotherapy arm of the AMAROS trial, $n=26$ ), or inability to retrieve a visualized axillary SLN $(n=5$; the surgical success rate of SLN retrieval was $99.4 \%)^{5}$

For the SLNB a 1-day protocol was used. The visualization and identification of SLNs consisted of preoperative lymphoscintigraphy and the intraoperative use of a $\gamma$-ray detection probe together with patent blue dye (Bleu patenté V, Laboratoire Guerbet, Aulnay-sous-Bois, France). Injections were given peritumorally and subcutaneously directly above the tumor. In nonpalpable breast tumors injections were guided by an ultrasound probe or a radiologically placed wire. Imaging was done directly after the nanocolloid injection and $2 \mathrm{~h}$ later. In the afternoon of the same day patients were operated on. Axillary SLNs were retrieved first and sent for FS analysis. Subsequently, internal mammary (IM) SLNs were collected when visualized on preoperative lymphoscintigraphy. These internal mammary SLNs were not sent for FS analysis. Detailed information about this procedure was published previously. ${ }^{6}$

In the pathology department the SLNs were isolated from fatty tissue, bisected longitudinally, separately formalin-fixed, paraffin embedded, and frozen in liquid nitrogen. The first complete cut from both halves was stained with hematoxylin and eosin (H\&E) and examined for the presence of metastases by the pathologist. The result of the FS analysis was reported to the operating surgeon a median 22 min after removal of the axillary SLNs and usually before the surgery for the primary breast tumor was completed. If FS confirmed the presence of metastases in the SLN, an ALND was done. An ALND consisted of the removal of all axillary fat from levels I and II and as much as from level III as could be obtained through the axillary incision.

Postoperatively, the remaining tissue of the axillary SLNs and IM SLNs were fixated in formalin and embedded in paraffin. The presence of lymph node metastases was investigated by examining 5 cuts from both halves of the node, $250 \mu \mathrm{m}$ apart, with $\mathrm{H} \& \mathrm{E}$ and immunohistochemical techniques staining for cytokeratin-8 (IHC). The examining pathologist assessed tumor diameter, the adjusted Bloom Richardson grade (BR-grade), Mitotic Activity Index (MAI), hormonal receptor status (estrogen receptor (ER), and progesterone receptor (PR)) for all patients and HER2/ neu status from 2004 on. $^{7}$ The presence of lymph node metastases was classified according to the 2002 version of the UICC-TNM-classification. ${ }^{8}$

When the intraoperative FS did not show metastases but the definitive histology did reveal lymph node metastases, patients were advised to undergo a second operation to perform a complementary ALND. Lymph nodes from the complementary ALND specimen were fixated in formalin, embedded in paraffin, and 2 cuts from the center of the node were examined after staining with H\&E and IHC.

The indication for subsequent nonsurgical treatment was determined applying the Dutch national guidelines (2008, version 1.1). ${ }^{9}$ In summary: (1) Adjuvant systemic chemotherapy is advocated in patients younger than 70 years and in the presence of lymph node (macro) metastases, or when the tumor diameter exceeds $2 \mathrm{~cm}$, or when the tumor is larger than $1 \mathrm{~cm}$ and the BR grade is II or III. (2) Adjuvant hormonal therapy is advocated under similar conditions, given ER-positive status of the tumor, but irrespective of age. (3) Radiotherapy other than as part of breast-conserving therapy and irrespective of tumor size is indicated when $\geq 4$ axillary lymph nodes or level III axillary lymph nodes contain metastases. Locoregional radiotherapy is then advocated. When IM SLNs contain metastases (and axillary SLNs not) radiotherapy of the parasternal and midclavicular field is indicated. Follow-up started at the date of the first operative procedure. Dates of death and locoregional recurrence were recorded prospectively until the last patient visit between October 2007 and May 2008.

The frequency of a "positive" FS result, that is, SLN metastases present, and the frequency of discordance between the intraoperative FS result "no metastasis" and the finding of lymph node metastases in the formalin-fixated and cytokeratin-stained additional cuts of the SLN were assessed. The metastatic burden in the 2 groups, 
reflected in the respective TNM N classes was compared using chi-square analysis.

Then, for patients who underwent a postponed ALND after a discordant FS result, the proportion of patients with additional lymph node metastases was analyzed as well as the proportion of these latter patients with an increased TNM N class. The advice for subsequent nonsurgical treatment was determined after the first operation and again after the postponed ALND, and we evaluated how often the complementary ALND led to adjustment of nonsurgical treatment.

Lastly, we compared cumulative overall survival and the occurrence of locoregional relapses for the 3 groups delineated by the FS and the definitive pathology examination result.

\section{RESULTS}

The median age of the 879 patients was 60 years (range 24-92); the clinicopathologic characteristics are summarized in Table 1. In addition to the axillary SLNs that were removed in all patients inherent to the selection of patients, IM SLNs were visualized on the preoperative lymphoscintigraphy in 193 patients. These IM SLNs were successfully removed in $157(81 \%)$ of the patients.

Axillary lymph node metastases were detected in 359 patients: in the SLN by intraoperative FS $(n=200)$, in the SLN after the definitive pathology examination (discordant FS result; $n=151$ ), in an axillary, non-SLN, not examined by FS $(n=4)$, or within the removed breast tissue, that is, intramammary $(n=4)$. Also, 42 patients had IM lymph node metastases (27\%), usually in combination with axillary metastases. Isolated IM metastases were found in 9 patients. A total of 511 patients (58\%) had no lymph node metastases.

Intraoperative FS analysis detected axillary metastases in 200 patients (23\%). See Fig. 1. In these patients, a direct complementary ALND revealed additional metastases in 101 patients (51\%). Definitive lymph node status was classified as: $\mathrm{N}_{1 \mathrm{mi}}(n=10), \quad \mathrm{N}_{1} \quad(n=133), \geq \mathrm{N}_{2} / \mathrm{N}_{3}$ $(n=57)$. See Table 2 .

In 151 patients the FS result was discordant with the result of the definitive pathology examination: axillary lymph node metastases were found only after the definitive examination of the serial sectioned lymph nodes (17\%). A second operation to perform a complementary ALND was not done in 39 of them (26\%) for various reasons: age or frailty of the patient $(n=25)$, an already existing indication for parasternal radiotherapy due to metastases in IM SLNs $(n=5)$, a synchronous contralateral breast cancer with preoperatively proven lymph node metastases $(n=2)$, or unknown $(n=7)$.
TABLE 1 Clinicopathologic characteristics of the patients

\begin{tabular}{|c|c|}
\hline Characteristic & No. $(\%)$ \\
\hline Patients $(n)$ & $879(100)$ \\
\hline Age (years): median (range) & $59.6(24.2-92.1)$ \\
\hline \multicolumn{2}{|l|}{ Tumor size $(\mathrm{cm})$} \\
\hline$<1$ & $106(12)$ \\
\hline $1-2$ & $461(52)$ \\
\hline $2-3$ & $231(26)$ \\
\hline$>3$ & $74(8)$ \\
\hline Unknown & $7(1)$ \\
\hline \multicolumn{2}{|l|}{ Definitive nodal status } \\
\hline $\mathrm{N}_{0}$ & $511(58)$ \\
\hline $\mathrm{N}_{\mathrm{itc}}$ & $24(3)$ \\
\hline $\mathrm{N}_{1 \text { micro }}$ & $95(11)$ \\
\hline $\mathrm{N}_{1 \mathrm{a}}$ & $158(18)$ \\
\hline $\mathrm{N}_{1 \mathrm{~b}}$ & $9(1)$ \\
\hline $\mathrm{N}_{1 \mathrm{c}}$ & $20(2)$ \\
\hline $\mathrm{N}_{2 \mathrm{a}}$ & $38(4)$ \\
\hline $\mathrm{N}_{3 \mathrm{a}}$ & $17(2)$ \\
\hline $\mathrm{N}_{3 b}$ & $7(1)$ \\
\hline \multicolumn{2}{|l|}{ Bloom Richardson grade } \\
\hline 1 & $368(42)$ \\
\hline 2 & $337(38)$ \\
\hline 3 & $164(19)$ \\
\hline Unknown & $10(1)$ \\
\hline \multicolumn{2}{|l|}{ Estrogen receptor status } \\
\hline Positive & $759(86)$ \\
\hline Negative & $119(14)$ \\
\hline Unknown & $1(0)$ \\
\hline \multicolumn{2}{|l|}{ Progesterone receptor status } \\
\hline Positive & $584(66)$ \\
\hline Negative & $293(34)$ \\
\hline Unknown & $2(0)$ \\
\hline \multicolumn{2}{|l|}{ HER2/neu status } \\
\hline Positive & $75(9)$ \\
\hline Negative & $667(76)$ \\
\hline Unknown $^{\mathrm{a}}$ & $137(15)$ \\
\hline \multicolumn{2}{|l|}{ Histopathologic type } \\
\hline Ductal & $744(85)$ \\
\hline Lobular & 108 (12) \\
\hline Tubular & $9(1)$ \\
\hline Other & $14(2)$ \\
\hline Unknown & $4(0)$ \\
\hline
\end{tabular}

${ }^{a}$ Before 2004, HER2/neu status was not routinely analyzed

In the 112 patients who underwent ALND as a secondary operation because of discordance between FS and definitive pathology examination of the SLN, the pathological findings of the ALND specimen revealed additional lymph node metastases in 17 patients (15\%). Compared 


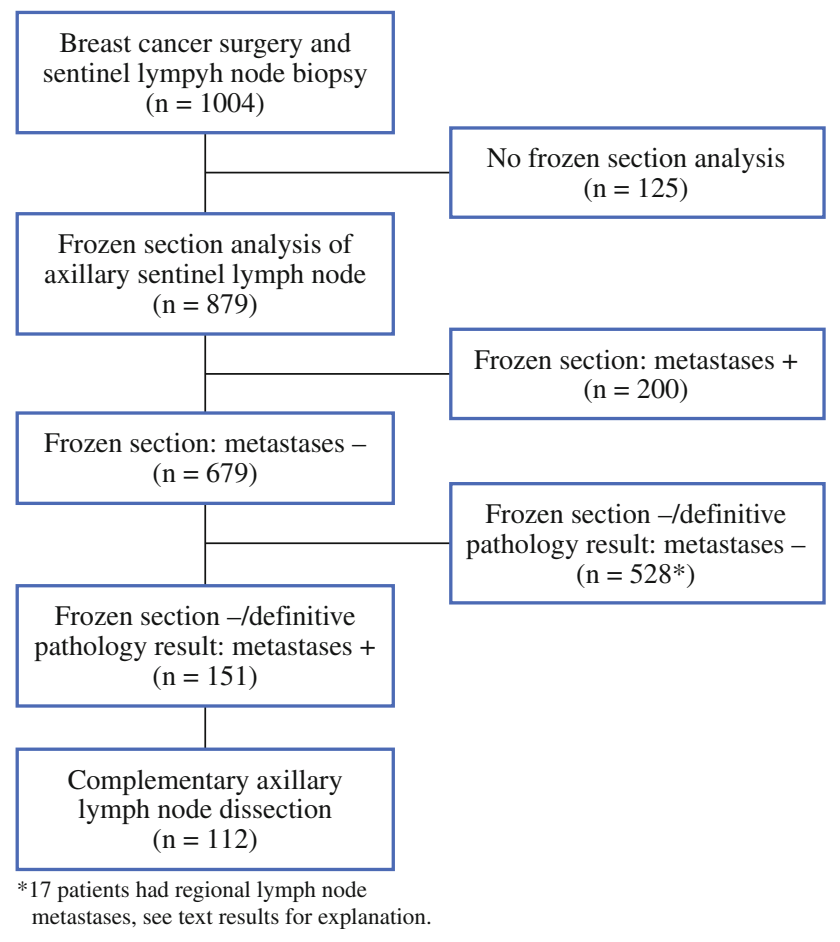

FIG. 1 Summary of axillary lymph node staging

with the group of patients with "positive" FS results, the metastatic burden in the regional lymph nodes was significantly less in the group with discordant FS results $(P<.001$; Table 2$)$.

The finding of additional lymph node metastases in 17 patients resulted in a higher UICC TNM N class in seven patients $(6 \%$, Table 3$)$. When applying the Dutch national

TABLE 2 Metastatic lymph node involvement (UICC-TNM N classes) in relation to the detection of metastases by frozen section analysis or after definitive pathology examination of the sentinel lymph node

\begin{tabular}{llcc}
\hline N stage & $\begin{array}{l}\text { FS: metastases }+ \\
n=200^{\mathrm{a}}\end{array}$ & $\begin{array}{l}\text { FS: metastases }-/ \\
\text { definitive PA: metastases }+ \\
n=151^{\mathrm{a}}\end{array}$ & $P^{*}$ \\
\hline $\mathrm{N}_{\text {itc }}$ & - & $24(16)$ & $<.001$ \\
$\mathrm{~N}_{1 \mathrm{mi}}$ & $10(5)$ & $84(56)$ & \\
$\mathrm{N}_{1 \mathrm{a}}$ & $122(61)$ & $31(21)$ & \\
$\mathrm{N}_{1 \mathrm{c}}$ & $11(6)$ & $8(5)$ & \\
$\mathrm{N}_{2 \mathrm{a}}$ & $33(17)$ & $4(3)$ & - \\
$\mathrm{N}_{3 \mathrm{a}}$ & $17(9)$ & - & \\
$\mathrm{N}_{3 \mathrm{~b}}$ & $7(4)$ & - \\
\hline
\end{tabular}

Values in parentheses are percentages. Definitive $\mathrm{N}$ status as determined after definitive surgery, including the findings in the IM SLNs

a 3 patients in the FS + group and 39 patients in the other group did not have an ALND; $\mathrm{N}$ class was based on the examination of the SLN(s). See text results

* Chi-square analysis guidelines, the findings of the subsequent ALND resulted in adjustment of subsequent nonsurgical treatment in 4 patients $(4 \%)$. These 4 patients were advised to receive more extensive locoregional radiotherapy. No patient would have received additional hormonal and/or chemotherapy based on the complementary ALND (Table 4).

After a median follow-up of 40 months the estimated cumulative 5-year overall survival was $90 \%$ in the group of patients with a discordant FS result, compared with $94 \%$ in the group who had no axillary metastases and $80 \%$ in the group who had metastases that were detected by FS analysis $(P<.001 ; \log$-rank test $)$. At the end of follow-up, locoregional relapses had been detected in $1(0.7 \%), 4$ $(0.8 \%)$ and 6 patients (3\%), respectively. None of the 39 patients who had metastases in the SLN but did not undergo a postponed ALND developed an axillary relapse.

\section{DISCUSSION}

In this prospective cohort of breast cancer patients, discrepancy between "negative" frozen section analysis and the definitive pathology examination of SLNs was common, occurring in $17 \%$ of all patients and in almost half of the patients with lymph node metastases. In this selection of patients, an ALND as a secondary operation revealed additional metastases in $17 \%$ of the patients, influencing subsequent radiotherapy in a small proportion of patients. Adjuvant systemic treatment (hormonal and/or chemotherapy) was not adjusted.

The present study describes a large cohort of consecutive breast cancer patients operated since the introduction of the SLNB in our hospital. Despite the volume of the overall group, the cohort of interest (i.e., the selection of 151 patients with discordant FS results in whom ALND as a second operation was indicated) was still modest. In addition, limiting the study group and introducing a potential source of selection bias, a substantial number of patients had no complementary ALND after the discordant FS result.

Discordance between FS analysis and the definitive pathology result was common, occurring in $17 \%$ of the patients operated for cT1-2N0 breast cancer. In itself, this is not surprising since serial sectioning will reveal the smaller metastases that go unnoticed when examining 2 cuts from the center of a lymph node when intraoperative frozen section analysis is done. As one would expect, discrepancy between frozen section and definitive pathology examination was strongly related to minimal lymph node involvement. ${ }^{3,10-12}$ Apparently, FS analysis can discriminate reliably between gross and limited (or no) metastatic lymph node involvement.

Many studies have addressed the chances of additional non-SLN lymph node metastases in patients with 
TABLE $3 \mathrm{~N}$ class adjustment as the result of complementary ALND in patients with discordant FS results of SLNs $(n=7)$

\begin{tabular}{|c|c|c|c|c|c|c|}
\hline $\begin{array}{l}\text { Patient } \\
\text { No. }\end{array}$ & $\begin{array}{l}\text { Tumor positive } \\
\text { axillary SLNs }(n)\end{array}$ & $\begin{array}{l}\text { Diameter of axillary } \\
\text { metastasis }(\mathrm{mm})\end{array}$ & $\begin{array}{l}\text { Tumor positive } \\
\text { IM SLNs }(n)\end{array}$ & $\begin{array}{l}\mathrm{N} \text { class after } \\
1 \text { st surgery }\end{array}$ & $\begin{array}{l}\text { Extra tumor positive } \\
\text { LNs after ALND }\end{array}$ & $\begin{array}{l}\text { Definitive } \mathrm{N} \text { class } \\
\text { after ALND }\end{array}$ \\
\hline 1 & 2 & 1.1 & 0 & $\mathrm{~N}_{1 \mathrm{mi}}$ & +1 & $\mathrm{~N}_{1 \mathrm{mi}} \rightarrow \mathrm{N}_{1 \mathrm{a}}$ \\
\hline 2 & 1 & 0.7 & 0 & $\mathrm{~N}_{1 \mathrm{mi}}$ & +1 & $\mathrm{~N}_{1 \mathrm{mi}} \rightarrow \mathrm{N}_{1 \mathrm{a}}$ \\
\hline 3 & 1 & 1.3 & 0 & $\mathrm{~N}_{1 \mathrm{mi}}$ & +2 & $\mathrm{~N}_{1 \mathrm{mi}} \rightarrow \mathrm{N}_{1 \mathrm{a}}$ \\
\hline 4 & 1 & $>2$ & 0 & $\mathrm{~N}_{1 \mathrm{a}}$ & +5 & $\mathrm{~N}_{1 \mathrm{a}} \rightarrow \mathrm{N}_{2 \mathrm{a}}$ \\
\hline 5 & 2 & $>2$ & 0 & $\mathrm{~N}_{1 \mathrm{a}}$ & +3 & $\mathrm{~N}_{1 \mathrm{a}} \rightarrow \mathrm{N}_{2 \mathrm{a}}$ \\
\hline 6 & 1 & 3.5 & 0 & $\mathrm{~N}_{1 \mathrm{a}}$ & +3 & $\mathrm{~N}_{1 \mathrm{a}} \rightarrow \mathrm{N}_{2 \mathrm{a}}$ \\
\hline 7 & 2 & $>2$ & 0 & $\mathrm{~N}_{1 \mathrm{a}}$ & +2 & $\mathrm{~N}_{1 \mathrm{a}} \rightarrow \mathrm{N}_{2 \mathrm{a}}$ \\
\hline
\end{tabular}

$S L N s$ sentinel lymph nodes, $A L N D$ axillary lymph node dissection, $L N s$ lymph nodes, $I M$ internal mammary chain

TABLE 4 Adjustment of subsequent nonsurgical treatment in patients with a higher $\mathrm{N}$ class after the complementary ALND following discordant FS results of SLNs $(n=7)$

\begin{tabular}{|c|c|c|c|c|c|c|c|c|c|c|}
\hline \multirow[t]{2}{*}{$\begin{array}{l}\text { Patient } \\
\text { (No.) }\end{array}$} & \multirow[t]{2}{*}{$\begin{array}{l}\text { Age } \\
\text { (y) }\end{array}$} & \multirow[t]{2}{*}{$\begin{array}{l}\text { Definitive } \mathrm{N} \text { stage } \\
\text { after ALND }\end{array}$} & \multicolumn{4}{|c|}{ Tumor characteristics } & \multicolumn{3}{|c|}{$\begin{array}{l}\text { Proposed postsurgical treatment } \\
\text { after first operation (SNB and FS) }\end{array}$} & \multirow{2}{*}{$\begin{array}{l}\text { Definitive treatment after } \\
\text { second operation (ALND) } \\
\text { Treatment adjustment? }\end{array}$} \\
\hline & & & $\begin{array}{l}\text { Tumor } \\
\text { size }(\mathrm{cm})\end{array}$ & HER2/neu & $\mathrm{ER} / \mathrm{PR}$ & $\begin{array}{l}\text { BR } \\
\text { grade }\end{array}$ & RT & $\mathrm{CT}(\mathrm{Y} / \mathrm{N})$ & $\mathrm{HT}(\mathrm{Y} / \mathrm{N})$ & \\
\hline 1 & 77 & $\mathrm{~N}_{1 \mathrm{mi}} \rightarrow \mathrm{N}_{1 \mathrm{a}}$ & 4.8 & - & $-1-$ & 3 & No & No & No & No \\
\hline 2 & 43 & $\mathrm{~N}_{1 \mathrm{mi}} \rightarrow \mathrm{N}_{1 \mathrm{a}}$ & 2.3 & - & $-1-$ & 2 & loco & Yes & No & No \\
\hline 3 & 62 & $\mathrm{~N}_{1 \mathrm{mi}} \rightarrow \mathrm{N}_{1 \mathrm{a}}$ & 6 & - & $+/+$ & 1 & prot & Yes & Yes & No \\
\hline 4 & 57 & $\mathrm{~N}_{1 \mathrm{a}} \rightarrow \mathrm{N}_{2 \mathrm{a}}$ & 2.1 & $\mathrm{U}$ & $+1-$ & 1 & No & Yes & Yes & Yes, loco RT \\
\hline 5 & 46 & $\mathrm{~N}_{1 \mathrm{a}} \rightarrow \mathrm{N}_{2 \mathrm{a}}$ & 2.2 & - & $+/-$ & 1 & No & Yes & Yes & Yes, loco RT \\
\hline 6 & 75 & $\mathrm{~N}_{1 \mathrm{a}} \rightarrow \mathrm{N}_{2 \mathrm{a}}$ & 1.1 & - & $+/+$ & 2 & No & No & Yes & Yes, loco RT \\
\hline 7 & 49 & $\mathrm{~N}_{1 \mathrm{a}} \rightarrow \mathrm{N}_{2 \mathrm{a}}$ & 2.1 & - & $+/+$ & 1 & prot & Yes & Yes & Yes, loco RT \\
\hline
\end{tabular}

$S N B$ sentinel node biopsy, FS frozen section, $A L N D$ axillary lymph node dissection, $R T$ radiotherapy, loco locoregional, prot according to protocol, $C T$ chemotherapy, $H T$ hormonal therapy, $B R$ Bloom-Richardson grade, $E R / P R$ estrogen-progesterone receptor status, $U$ unknown

micrometastases in SLNs. Because most of the patients with discordance between the FS and definitive pathology result had micrometastases in their SLNs, the observed frequency of additional metastases following the postponed ALND is unsurprisingly similar to the reported proportions of non-SLN metastases in patients with SLNs with micrometastases. $^{3,4}$ Observing additional metastases in approximately $15 \%$ of the patients who underwent a postponed ALND, most authors underline the importance of a complementary ALND. ${ }^{4,13}$

No studies, to our knowledge, investigated the clinical consequences of the ALND in the selection of patients who had discordant frozen section results. In this selection of patients the metastatic lymph node involvement is limited and remains so after the postponed ALND. While additional metastases were quite common, extra adjuvant systemic treatment was never advised, while more extensive (locoregional) radiotherapy was proposed in less than $5 \%$ of the patients. These very limited clinical implications of the postponed ALND were surprising. Then again, recent data suggest that even limited lymph node involvement has an adverse prognostic effect on outcome, and the authors advocate adjuvant systemic therapy in all patients with micrometastases and isolated tumor cells. ${ }^{14}$ In that perspective, a postponed ALND would by definition have no effect on systemic therapy.

In contrast to the limited implications of the ALND after a discordant FS result, extensive metastatic lymph node involvement, that is, TNM class $\mathrm{N}_{2}$ or $\mathrm{N}_{3}$, was found in more than one-quarter of the patients when FS analysis revealed lymph node metastases intraoperatively, and ALND was done instantly. This necessitated extension of the radiotherapy field and potentially led to more intensive chemotherapy in a similar proportion.

The primary objective of intraoperative FS analysis of axillary SLNs is sparing patients a second operative procedure. In addition, the present data demonstrate that when there is discrepancy between a negative FS analysis and a tumor-positive definitive pathology result, the ALND is merely advised for locoregional control decreasing the risk of axillary recurrence in the future by removing additional metastases in non-SLNs in a substantial proportion of patients and by necessitating extension of the radiotherapy treatment in a small proportion of patients. However, 
ALND as a procedure to improve locoregional control has been under debate well before the era of the SLN procedure. This makes the case for routine ALND in this category of patients with very limited metastatic lymph node involvement questionable. ${ }^{15}$

Radiotherapy of the axilla is currently under investigation in a randomized trial (EORTC 10981 AMAROS trial), evaluating the role of radiotherapy as a substitute for ALND in patients with metastases-containing SLNs. ${ }^{5}$ If this trial will document similar locoregional control rates, radiotherapy will be a proper alternative for axillary treatment that will probably be preferred by many women and clinicians. In patients with gross metastatic lymph node involvement, ALND may still be desirable to obtain optimal staging information that will influence nonsurgical treatment in a one-quarter of the patients. When metastases are only detected by the definitive pathology examination, ALND will very rarely lead to postsurgical treatment changes. These latter patients will be very good candidates for radiotherapy to the axilla obviating the need for a postponed ALND.

OPEN ACCESS This article is distributed under the terms of the Creative Commons Attribution Noncommercial License which permits any noncommercial use, distribution, and reproduction in any medium, provided the original author(s) and source are credited.

\section{REFERENCES}

1. Giuliano AE, Dale PS, Turner RR, Morton DL, Evans SW, Krasne DL. Improved axillary staging of breast cancer with sentinel lymphadenectomy. Ann Surg. 1995;3:394-401.

2. Miltenburg DM, Miller C, Karamlou TB, Brunicardi FC. Metaanalysis of sentinel lymph node biopsy in breast cancer. $J$ Surg Res. 1999;84:138-42.
3. Wada N, Imoto S, Hasebe T, Ochiai A, Ebihara S, Moriyama N. Evaluation of intraoperative frozen section diagnosis of sentinel lymph nodes in breast cancer. Jpn J Clin Oncol. 2004;34:113-7.

4. Cserni G, Gregori D, Merletti F, Sapino A, Mano MP, Ponti A, et al. Meta-analysis of non-sentinel node metastases associated with micrometastatic sentinel nodes in breast cancer. Br J Surg. 2004;91:1245-52.

5. EORTC-AMAROS trial 10981: After mapping of the axilla: radiotherapy or surgery?

6. Madsen EVE, Gobardhan PD, Bongers V, Albregts M, Burgmans $\mathrm{J}$, De Hooge P, et al. The impact on post-surgical treatment of sentinel lymph node biopsy of internal mammary lymph nodes in patients with breast cancer. Ann Surg Oncol. 2007;14:1486-96.

7. Elston CW, Ellis IO. Pathological prognostic factors in breast cancer. The value of histological grade in breast cancer: experience from a large study with long-term follow-up. Histopathology. 1991;19:403-10.

8. Sobin ELH, Wittekind Ch. UICC TNM Classification of Malignant Tumours. New York: Wiley-Liss, 2002.

9. Dutch National Guideline Breast Carcinoma, Sep 2008; version 1.1. http://www.oncoline.nl.

10. Grabau DA, Frank F, Friis E. Intraoperative frozen section examination of axillary sentinel lymph nodes in breast cancer. APMIS. 2005;113:7-12.

11. Chao C, Wong SL, Ackermann D, Simpson, Simpson D, Carter $\mathrm{MB}$, Brown CM, et al. Utility of intraoperative frozen section analysis of sentinel lymph nodes in breast cancer. Am J Surg. 2001;182:609-15.

12. Weiser MR, Montgomery LL, Susnik B, Tan LK, Borgen PI, Cody HS. Is routine intraoperative frozen-section examination of sentinel lymph nodes in breast cancer worthwhile? Ann Surg Oncol. 2000;7:651-5.

13. Christiansen P, Friis E, Balslev E, Jensen D, Møller S. Sentinel node biopsy in breast cancer: Five years experience from Denmark. Acta Oncol. 2008;47:561-8.

14. de Boer M, van Deurzen CH, van Dijck JA, Borm GF, van Diest PJ, Adang EM, et al. Micrometastases or isolated tumor cells and outcome of breast cancer. New Engl J Med. 2009;361:653-63.

15. Lyman GH, Giuliano AE, Somerfield MR, Benson AB 3rd, Bodurka DC, Burstein HJ, et al. American Society of Clinical Oncology Guideline Recommendations for sentinel lymph node biopsy in early-stage breast cancer. J Clin Oncol. 2005;23:7703-20. 